\title{
New Mars meteorite fall in Marocco: final strewn field
}

\author{
Abderrahmane Ibhi \\ Laboratory of Geo-heritage and Geo-materials Science, Ibn Zohr University, Agadir, Morocco
}

E-mail address: a.ibhi@uiz.ac.ma

\section{ABSTRACT}

The Tissint fireball is the only fireball to have been observed witnesses across the south-east of Morocco. The event was extrem community; show an extraordinary and rare event and were lso the at and most comprehensively observed fireball in Morocco's known astronom cal ory. Since re abstract of A. Ibhi (2011) [1]. In 2012-2013 concerning a number of Martian orite nents found in the region of Tata (Morocco), a number of expeditions have been $\mathrm{n}$ ade $\mathrm{w}$ the area. Thi has done a great amount of field work. He discovered the strewn field ad collected the fyagments of this Martian meteorite and many information. Each expedition has id the effect of expanding the size of the strewn field which is now documented to cover more th 70 sq. kil meters. The size of the strewn field is now estimated to be about a $17 \mathrm{~km}$ long

Keywords: fireball; Martian meteorite; Shergottit Stry -1d, Tissint; Morocco

\section{INTRODUCTION}

A meteoritic bra) ntered the arth's atmosphere in the south-east skies of Tata, Morocco, On Sunda. July, th, 2011 at 2 o'clock in the morning. Its interaction with the atmosphere led to brilliant by flashes accompanied with detonations. The apparent magnitude of the fir all was bighter than -20. A large number of fragments survived the fireball pheno. The sarian nomads living in the surrounding region then came together for searching tho bris of his extraterrestrial rock. The first fragment had been discovered at the a o cembu a cout a hundred persons came to the region of Tissint (Tata, Morocco) ap. hout ffty fragnients had been collected by the nomads, traders and hunters with some know e aum xtraterrestrial rocks. This extraterrestrial debris became a source of revenue and this lains the trade value of these rocks, which appears to be reached 700 dollars for one gram, $y$ be paid directly in cash in the desert.

Ahmed Sghiwar, a nomad who found a small block of 5 grams in the region, contacted at the beginning of January 2012 the author, Prof. Ibhi Abderrahmane, scientist and collector of meteorites at the Ibn Zohr University in order to inform him about the findings of freshly fallen meteorites in the region of Tata. In 1012-2013 a number of expeditions have been made to the fall area equipped with a modern navigation and detection instruments. The member of this team succeeded in collecting debris of this Martian meteorite and information on the fall. 
We present in this paper results of systematic search made over a period of one month to collect the data of this meteorite which has been named as Tissint, where a large number of fragments were found within a seven months of the fall.

\section{THE MARTIAN OF TISSINT, COLLECTING OBSERVATIONS}

The meteorite of Tissint is the first fall of a Martian meteorite observed in Morocco and the 5th worldwide [2]. Historically, watched falls took place only once in 50 years more (1815 in France, 1865 in India, 1911 in Egypt and 1962 in Nigeria). This is once in the or of a human being. The following table (Table 1) gives the details of the five is of Mart meteorites.

Table 1. Date of discovery and classification of Martian me rite fa

\begin{tabular}{|c|c|c|c|c|}
\hline Name & Find Location & Year & Cla sification & 1ass (kg) \\
\hline Chassigny & Marne, France & 1815 & & ( \\
\hline Shergotty & Bihar, India & 1865 & Basalt & 5 \\
\hline Nakhla & Alexandria, Egypt & 1911 & Clino yroxenite & 10 \\
\hline Zagami & Katsina, Nigeria & & Basalt & 18 \\
\hline Tissint & Tata, Morocco & 20 & Basaltic shergottite & $>12$ \\
\hline
\end{tabular}

It is classified as

olivine-phyric shergottite, with olivine macrocrysts (up to $1.5 \mathrm{mp}$, and $\mathrm{m}$ phenocrysts (up to $0.4 \mathrm{~mm}$ ) set in a finer groundmass of patchily zoned pyroxer agioclase okelynite; An61.1-64.3Or0.5-0.4), Ti-poor chromite, ilmenite, pyrrhotite $\mathrm{d}$ merrill, e. Both the larger olivine macrocrysts (cores Fa19.420.2, $\mathrm{FeO} / \mathrm{MnO} 2-44)$ an maller olivine microphenocrysts $(\mathrm{Fa} 29.1-30.2 ; \mathrm{FeO} / \mathrm{MnO}=$

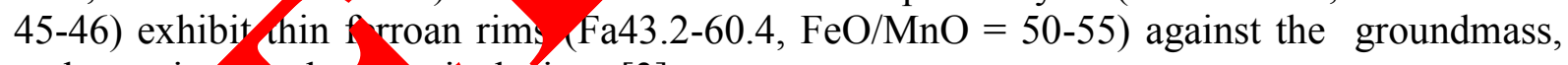
and contain chr mme clusions [3].

The noma of the $r$ gion of Tissint (a region in the east of Morocco, situated $60 \mathrm{~km}$ to the somin of th of Tata nearby the Moroccan-Algerian border) became to know that the eces rocks c rected nearby their camp of the beginning of January 2012 had been in fact $\quad$ Thes started a search for the other pieces of the same fall and indeed other $\mathrm{p}$ were found in a long drawn-out zone of about $15 \mathrm{~km}$ in length. Most fragments have a sm size, which is explained by the explosive nature of the bolide. Most fragments were found to have a well developed crust. 16 of the 51 fragments are completely crusted, 11 are partly crusted and 24 fragments have crusts only on a small fraction of the surface area (Fig. 1). In the sands of Oued El Myit and Oued Bou Ifasouan the men and women of the nomads used sieves in order to find debris if not even dust of this extraterrestrial rock. 

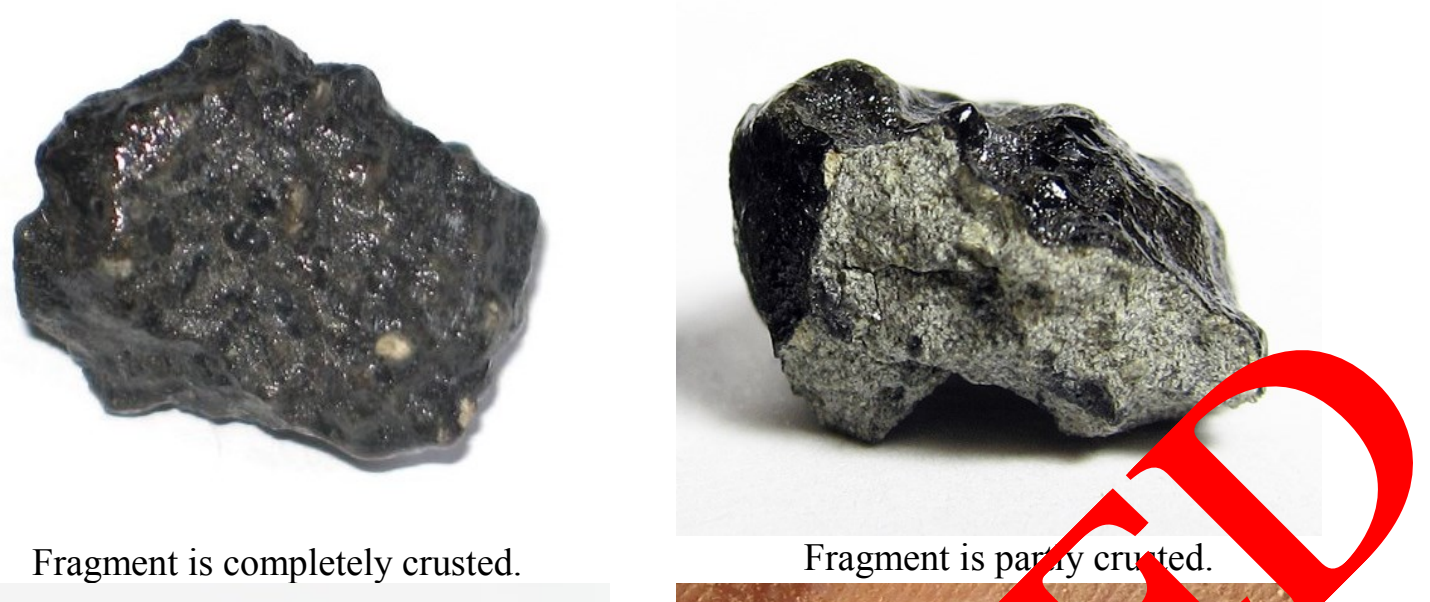

Fragment is completely crusted.

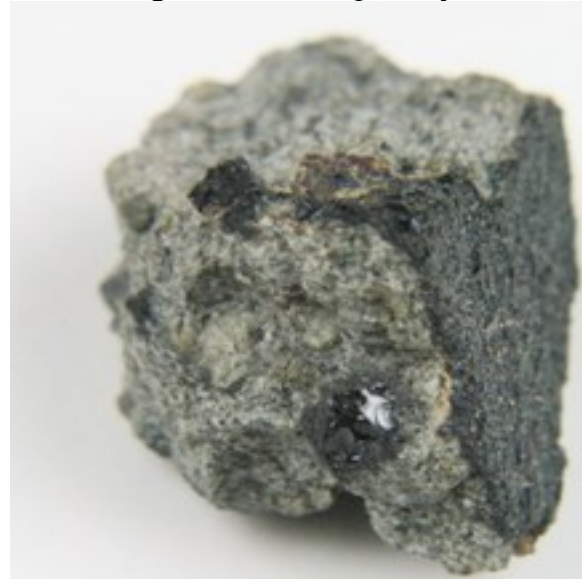

Crust only on a small fr

Fig. 1. Sam r of M rtian met srites Tissint (Tata, Morocco).

The bolide brok to parts, cen he entered the earth's atmosphere, throwing numerous fragments nto s. ar tracks ending in an extended zone called the ellipse of the fall. Further the onrads and th intary reported that it was at first yellow in color, and then turned green efore appeared to split into two parts. One portion appeared to fall in the valley, whice at er por on was seen to strike a prominent mountain (El Aglab). It is estimated that th olide Itered the Earth's atmosphere at a highly inclined angle southeast of Tra. fireba conated at a height of approximately $10 \mathrm{~km}$ above the point location 29 N N 036 ' W close to the Oued Drâa in the Tissint Region. An accurate speed has not been atmen, wever, on average, meteors and fireball move through the atmosphere at speeds $\mathrm{u}_{\mathrm{N}}$ and greater than $15 \mathrm{~km} / \mathrm{s}$.

\section{THE STREWNFIELD OF THE MARTIAN METEORITE OF TISSINT}

The strewnfield of Tissint is situated in about $60 \mathrm{~km}$ of linear distance to the south-east of Tata in the area of the rural commune of Tissint. It is covered within the topographic map 1: 100.000th of Tata (Fig. 2). The Lambert coordinates are $\mathrm{x}=280800$ and $\mathrm{y}=280100$ and the GPS coordinates are ' $29^{\circ} 31^{\prime} 2881 \mathrm{~N} ; 7^{\circ} 36^{\prime} 4472 \mathrm{~W}$ ". 


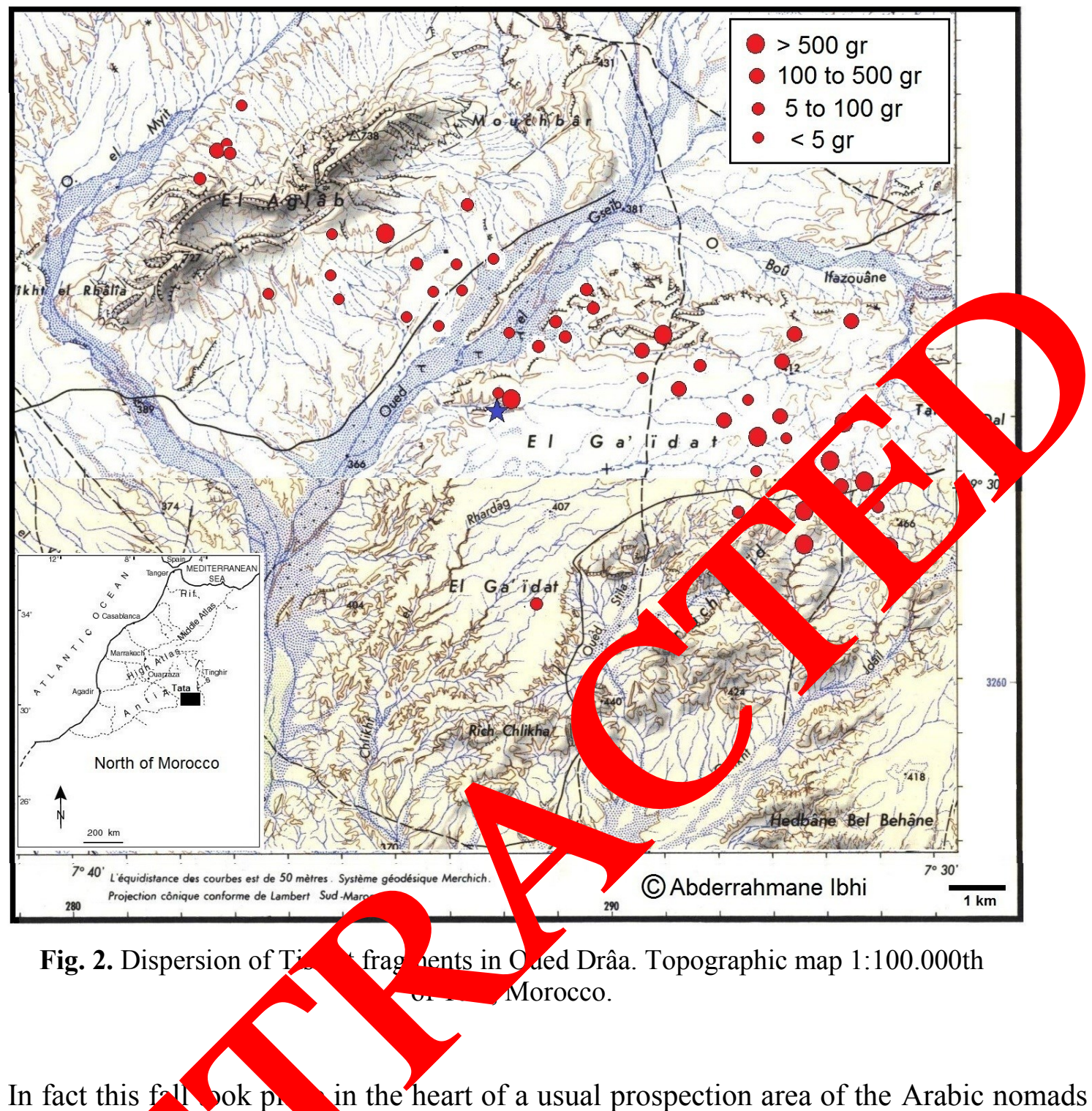

In fact this fall ok p in the heart of a usual prospection area of the Arabic nomads living in the mitary zone be on Morocco and Algeria, which have some knowledge of meteorites ar are lo ving for meteorites for the whole year on their wandering through the desert. In sevo eeks o a deep search the nomads collected about $12 \mathrm{~kg}$ of fragments of the meto ite, son of the not passing 1 gram.

the ficu uld tak onths to explore the entire ellipse of the fall due to the rough ground, of mo the ralling places had to be got in order to determine the strewn field of the meteorito Tata, so it had been necessary to move with 4WD cars and sometimes for narrow foot paths oven with motorbikes. Additionally the nomads had to be paid for leading the scientists to the places of their findings in order to get their coordinates. Each fragment found was coded and documented with respect to its position in the field.

The position of the fragments could be ascertained conveniently in the $1 \times 1 \mathrm{~km}$ grid map with respect to local landmarks (Fig. 3). To date a total of nominally 50 fragments weighing about $12 \mathrm{~kg}$ have been found. The largest fragment weighed $1100 \mathrm{~g}$ and was found accidentally, near the eastern tip of the strewnfield. An important reason for the low efficiency is the similar appearance of the crusted Tissint stones and the dark colored 
sandstone fragments found extensively in the strewnfield. The nomads, however, quickly learnt to distinguish meteorite pieces from native rock fragments.

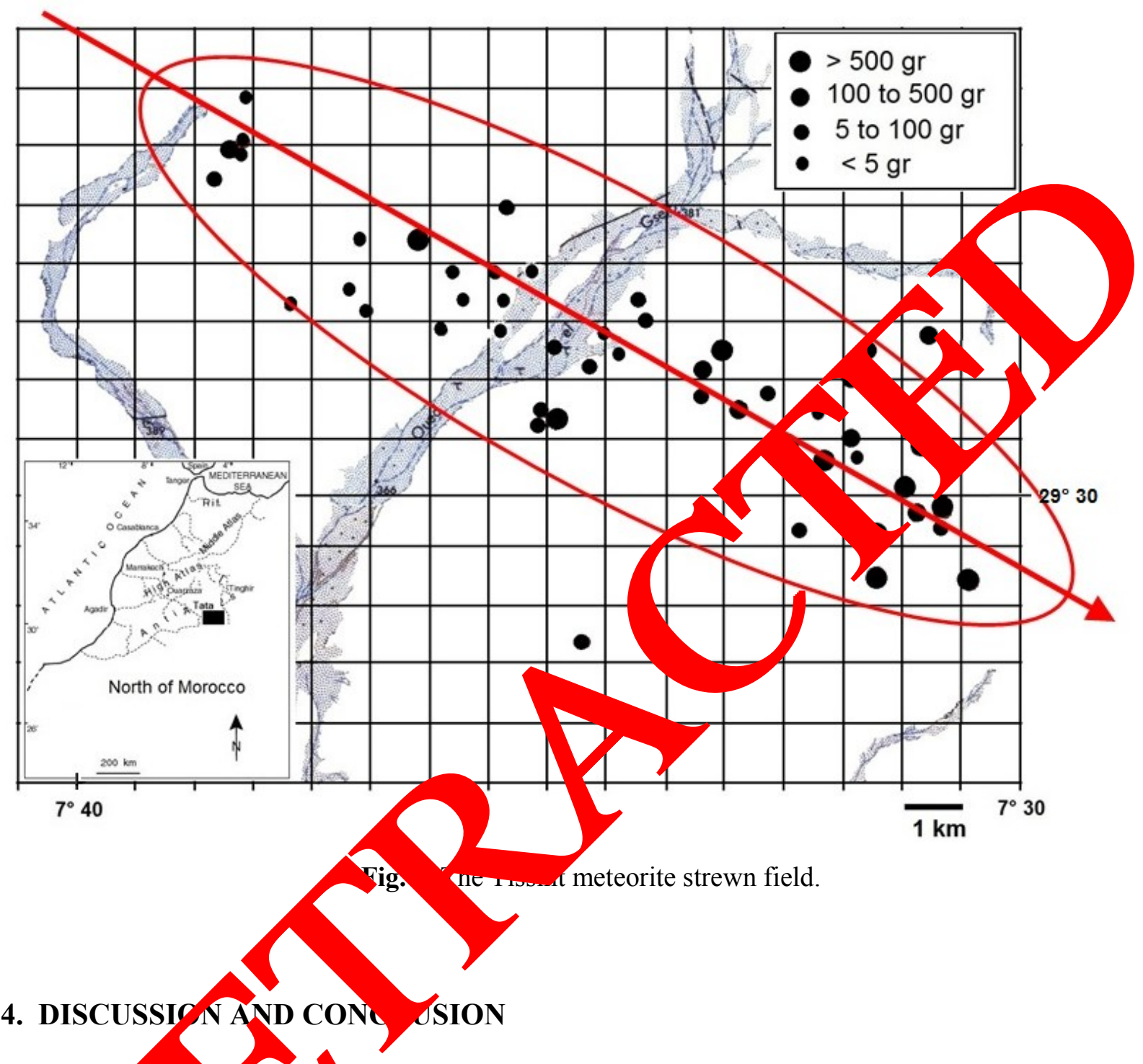

Since the 2000 discovering of meteorites in the hot desert of South Morocco increas s]. some of the samples have a very high scientific value. One counts acty 1ly 2 Morocc. Martian meteorites of 61 Martian meteorites found worldwide until to a ${ }^{a}$. 9]. Zagam 2 years earlier) and the first such olivine-phyric shergottite example [3].

In fold, we collected the coordinates of the most significant masses and met eyewitnesses. The coordinates are reported on the 1/100,000th map, with the inferred trajectory NW to SE. These information are in accordance with the reported testimonies.

The strewnfield of this meteorite fall extends at least $17 \mathrm{~km}$ from the west-north-west to eastsouth-east, which is also the flight direction of the meteorite after the observations of the nomads. More than 50 fragments of Tissint meteorite weighing about $15 \mathrm{~kg}$ have been recovered from the strewn field of $70 \mathrm{~km}^{2}$ area. Information about their position in the strewnfield is available in the case of practically all the fragments. Each fragment has been coded and information on the crusting of the surfaces has been documented. 
In view of the relatively high efficiency of collection for the Tissint fragments probably higher than for any of the meteorite showers reported earlier, we have made a detailed analysis of the number and mass distribution of meteorite fragments as well as their location in the strewnfield. These data are a true heritage and has to archived.

\section{Acknowledgements}

We thank the military, Al Ho and Ahmed Sghiwar nomads for their assistance in the collection of information. Finally, we thank Hassan Nachit and Diplomphys aus Schneider for discussions.

\section{References}

[1] Ibhi A., International Meteor Conference - La Palma Island,

[2] Nishiizumi K., Caffee M. W., Irving A. J., $75^{\text {th }}$ Annual M a itical Socm Meeting Cairns, Australia, 2012, Abstract No. 5349.

[3] Irving A. J., Kuehner S. M., Tanaka R., Herd C. D K., Chen G., L. M T. J., 43rd Lunar and Planetary Science Conference - Woodlands Texas, 2012, Abstract No. 2510.

[4] Russell Sara., Zipfel J., Folco Luigi, Jones R., G Iv M. M., Jc Coy T., Grossman J. M., Meteoritics \& Planet. Sci. 38 (2003) A189-A248.

[5] Connolly H. C. Jr, Zipfel J., Grossman J. W.., Smith C., Jones R. H., Righter K., Zolensky M., Russel S. S., Benedix G. K. Yz nay Mi A., Cohen B. A., Meteoritic and Planetary Science 41(9) (2006-1283-1418

[6] Connolly H. C. Jr, Zipfel J Folco L., Smith /., Jones R. H., Benedix G. K., Righter K., Yamaguchi A., Chenna Gi Grossman J. N., Meteoritic and Planetary Science 42(3) (2007) 413-466.

[7] Ibhi A., Nachit H A F. H., Fao Z1 A., Meteorite 15 (2009) 32-36.

[8] Ibhi A., Les cúrites di roc I. eds., U. E. (2011) 152 pages, ISBN-978-3841787590.

[9] Stephen R., G ge M., Russell S., $75^{\text {th }}$ Annual Meteoritical Society Meeting - Cairns, Australia, 2o, Abstr t No. 5234.

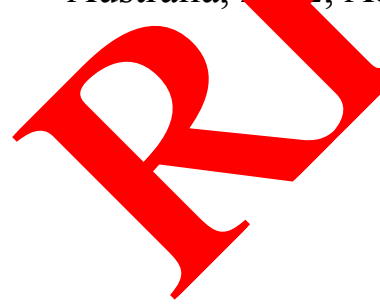

( Received 13 July 2013; accepted 17 July 2013 ) 